\title{
THE
}

\section{Ischemia-reperfusion impairs blood-brain barrier function and alters tight junction protein expression in the ovine fetus}

X. Chen

S. W. Threlkeld

E. E. Cummings

I. Juan

O. Makeyev

University of Rhode Island

See next page for additional authors

Follow this and additional works at: https://digitalcommons.uri.edu/ele_facpubs

This is a pre-publication author manuscript of the final, published article.

Creative Commons License

(c) $(i) \Theta($

This work is licensed under a Creative Commons Attribution-Noncommercial-No Derivative Works 4.0 License.

\section{Citation/Publisher Attribution}

Chen, X., Threlkeld, S. W., Cummings, E. E., Juan, I., Makeyev, O., Besio, W. G., Gaitanis, J.,...Stonestreet, B. S. (2012). Ischemia-reperfusion impairs blood-brain barrier function and alters tight junction protein expression in the ovine fetus. Neuroscience, 226, 89-100. doi: 10.1016/j.neuroscience.2012.08.043 Available at: https://doi.org/10.1016/j.neuroscience.2012.08.043

This Article is brought to you for free and open access by the Department of Electrical, Computer, and Biomedical Engineering at DigitalCommons@URI. It has been accepted for inclusion in Department of Electrical, Computer, and Biomedical Engineering Faculty Publications by an authorized administrator of DigitalCommons@URI. For more information, please contact digitalcommons-group@uri.edu. 
Authors

X. Chen, S. W. Threlkeld, E. E. Cummings, I. Juan, O. Makeyev, W. G. Besio, J. Gaitanis, W. A. Banks, G. B. Sadowska, and B. S. Stonestreet

This article is available at DigitalCommons@URI: https://digitalcommons.uri.edu/ele_facpubs/89 


\title{
Ischemia-reperfusion impairs blood-brain barrier function and alters tight junction protein expression in the ovine fetus
}

\author{
Xiaodi Chen ${ }^{1}$, Steven W. Threlkeld ${ }^{1,5}$, Erin E. Cummings ${ }^{1}$, Ilona Juan ${ }^{1}$, Oleksandr \\ Makeyev², Walter G. Besio $^{2}$, John Gaitanis ${ }^{3}$, William A. Banks ${ }^{4}$, Grazyna B. Sadowska ${ }^{1}$, \\ and Barbara S. Stonestreet ${ }^{1}$ \\ ${ }^{1}$ Department of Pediatrics, The Alpert Medical School of Brown University, Women \& Infants \\ Hospital of Rhode Island, Providence, RI, 02905 \\ ${ }^{2}$ Department of Electrical, Computer, and Biomedical Engineering, University of Rhode Island, \\ Kingston, RI 02881 \\ ${ }^{3}$ Department of Neurology, The Alpert Medical School of Brown University, Rhode Island \\ Hospital, Providence, RI \\ ${ }^{4}$ Geriatric Research Educational, and Clinical Center, Veterans Affairs Puget Sound Health Care \\ System, Division of Gerontology and Geriatric Medicine, Department of Internal Medicine, \\ University of Washington, Seattle, Washington
}

\begin{abstract}
The blood-brain barrier is a restrictive interface between the brain parenchyma and the intravascular compartment. Tight junctions contribute to the integrity of the blood-brain barrier. Hypoxic-ischemic damage to the blood-brain barrier could be an important component of fetal brain injury. We hypothesized that increases in blood-brain barrier permeability after ischemia depend upon the duration of reperfusion and that decreases in tight junction proteins are associated with the ischemia-related impairment in blood-brain barrier function in the fetus. Blood-brain barrier function was quantified with the blood-to-brain transfer constant $\left(K_{i}\right)$ and tight junction proteins by Western immunoblot in fetal sheep at 127 days-of-gestation without ischemia, and 4-, 24-, or 48-h after ischemia. The largest increase in $K_{i}(P<0.05)$ was 4-h after ischemia. Occludin and claudin-5 expressions decreased at 4-h, but returned toward control levels 24- and 48-h after ischemia. Zonula occludens- 1 and -2 decreased after ischemia. Inverse correlations between $K_{i}$ and tight junction proteins suggest that the decreases in tight junction proteins contribute to impaired blood-brain barrier function after ischemia. We conclude that impaired blood-brain barrier function is an important component of hypoxic-ischemic brain injury in the fetus, and that increases in quantitatively measured barrier permeability $\left(K_{i}\right)$ change as a function of the duration of reperfusion after ischemia. The largest increase in permeability occurs 4-h after ischemia and blood-brain barrier function improves early after injury because the blood-brain barrier is less
\end{abstract}

\footnotetext{
(C) 2012 IBRO. Published by Elsevier Ltd. All rights reserved.

Corresponding Author: Barbara S. Stonestreet, M.D., The Alpert Medical School of Brown University, Department of Pediatrics, Women and Infants Hospital of Rhode Island, 101 Dudley Street, Providence, RI 02905-2499, Phone: (401) 274-1122 ext. 7429, Fax: (401) 453-7571, bstonestreet@wihri.org.

5 Present Address: Steven Threlkeld Ph.D., Department of Psychology, Rhode Island College, 600 Mount Pleasant Ave, Providence RI, 02908

Publisher's Disclaimer: This is a PDF file of an unedited manuscript that has been accepted for publication. As a service to our customers we are providing this early version of the manuscript. The manuscript will undergo copyediting, typesetting, and review of the resulting proof before it is published in its final citable form. Please note that during the production process errors may be discovered which could affect the content, and all legal disclaimers that apply to the journal pertain.
}

DISCLOSURE

The authors have no duality or conflicts of interests to declare. 
permeable 24- and 48- than 4-h after ischemia. Changes in the tight junction molecular composition are associated with increases in blood-brain barrier permeability after ischemia.

\section{Keywords}

blood-brain barrier; brain; fetus; ischemia-reperfusion; ovine; tight junction proteins

The blood-brain barrier is composed of a continuous layer of endothelial cells connected by intercellular tight junctions (Betz and Goldstein, 1986) and serves as an interface between circulating blood, brain interstitium and parenchyma, maintaining central nervous system (CNS) homeostasis (Betz, 1992). Although the basement membrane, pericytes, and astrocyte end-feet processes are also important components of the neurovascular unit contributing to the integrity of the blood-brain barrier, the tight junctions of endothelial cells represent the primary restrictive barrier of the blood-brain barrier (Hawkins and Davis, 2005). Tight junctions are composed of transmembrane proteins, including claudins and occludin, which are the primary structures responsible for blood-brain barrier properties. Proteins of the claudin family form the primary seal between adjacent endothelial cells, whereas occludin functions as a support molecule increasing electrical resistance across the barrier and decreasing paracellular permeability (Hawkins and Davis, 2005). Zonula occludens (ZO)-1 and ZO-2, located at the cytoplasmic surface of endothelial cells, stabilize tight junctions by connecting them to actin (Hawkins and Davis, 2005).

Hypoxic-ischemic brain injury is the most common neurologic problem in the perinatal period (Vannucci, 1993) and could damage the integrity of the blood-brain barrier. We have shown that blood-brain barrier development takes place throughout fetal-neonatal development (Stonestreet et al., 1996). Although previous studies have shown that hypoxicischemic insults can damage the immature blood-brain barrier, the majority of studies have been carried out in rodent models (Fan et al., 2009, Leonardo and Pennypacker, 2009) and, consequently, the effects of ischemia have not been quantitatively determined with the blood-to-brain transfer constant in fetal subjects. Hence, information is not available regarding the effects of hypoxia-ischemia on quantitative changes in blood-brain barrier permeability, on the distribution of damage to different brain regions, or concerning potential mechanisms underlying the changes in barrier permeability in the immature brain, and particularly not in the brain of a precocial species such as sheep. Only two studies have examined blood-brain barrier function in the fetus exposed to hypoxia-ishemia (Lou et al., 1979, Tweed et al., 1981) and the results of these studies differ. Lou et. al found the bloodbrain barrier became leaky to the albumin-bound tracer Evans blue after prolonged umbilical cord occlusion (Lou et al., 1979), whereas, Tweed, et. al found the blood-brain barrier was relatively resistant to severe asphyxia (Tweed et al., 1981). Differences in the responses of the blood-brain barrier to hypoxia-ischemia have also been observed in newborn pigs (Temesvari and Kovacs, 1988, Mirro et al., 1991, Armstead et al., 1992, Stonestreet et al., 1992). Global ischemia and bilateral pneumothoracies have been shown to result in impaired blood-brain barrier function in newborn pigs (Temesvari and Kovacs, 1988, Mirro et al., 1991) whereas, increases in blood-brain barrier permeability were not detected after severe hypotensive-hypoxia/hypercarbia in newborn pigs (Stonestreet et al., 1992). The increases in barrier permebility that were observed in the newborn pigs after inducing global ischemia by increasing intracranial pressure above mean arterial blood pressure for 20 minutes followed by $30 \mathrm{~min}$ and $2 \mathrm{~h}$ of reperfusion (Mirro et al., 1991) may have represented a more severe ischemic insult compared with the hypotensive-hypoxia/hypercarbia insult on our previous study (Stonestreet et al., 1992). In addition, activated oxygen species appear to contribute to the ischemia-reperfusion related barrier dysfunction in the newborn pigs (Armstead et al., 1992). The response of the blood-brain barrier to hypoxia-ischemia also appears to vary in 
young rodents depending upon the duration of reperfusion and the age at the insult (Muramatsu et al., 1997).

Although biphasic opening of the blood-brain barrier after middle cerebral artery occlusion (MCAO) has been reported in adult rats (Kuroiwa et al., 1985, Belayev et al., 1996), the temporal and spatial pattern of blood-brain barrier abnormalities after ischemia has not been delineated in the fetus. The effectiveness and integrity of the tight junction seal between adjacent endothelial cells has been suggested to be critical to the homeostasis of the CNS in response to hypoxic-ischemic brain injury (Vaccarino and Ment, 2004). Although information regarding the effects of hypoxia-ischemia on the regulation of tight junctions in the immature brain is sparse, particularly in vivo, we have previously shown increased expression of claudin-5, decreased expression of ZO-1 and -2, and stable levels of occludin and claudin-1 measured 72-h after ischemia in fetal sheep (Malaeb et al., 2007).

In the current study, we examined the effects of reperfusion for 4-, 24-, or 48-h after 30 minutes of ischemia on blood-brain barrier function measured quantitatively with the bloodto-brain transfer constant $\left(K_{i}\right)$ and ischemia/reperfusion effects on tight junction proteins by Western immunoblot on fetal sheep brains harvested at 127 days-of-gestation. Given the above considerations, we hypothesized that 1) increases in blood-brain barrier permeability after ischemia depend upon the duration of reperfusion and that 2) decreases in tight junction proteins are associated with the ischemia-related impairment in blood-brain barrier function in the fetus.

\section{EXPERIMENTAL PROCEDURES}

The present study was conducted after approval by the Institutional Animal Care and Use Committees of the Alpert Medical School of Brown University and Women \& Infants Hospital of Rhode Island and in accordance to the National Institutes of Health Guidelines for the use of experimental animals.

\section{Animal Preparation, Study Groups, and Experimental Design}

Surgery was performed under 1-2\% isoflurane anesthesia on 20 mixed breed pregnant ewes at 120 to 122 days-of-gestation as previously described (Petersson et al., 2002). Briefly, polyvinyl catheters were placed in fetal brachial veins and arteries and in the femoral artery of the ewe for blood pressure and heart rate monitoring, as well as blood sampling (Petersson et al., 2002). An amniotic fluid catheter was placed as a referent for fetal arterial pressures.

The fetal carotid arteries were exposed, vertebral-occipital anastomoses and lingual arteries ligated to restrict blood flow from the vertebral circulation and non-cerebral blood flow, respectively (Gunn et al., 1997). Two inflatable 4-mm vascular occluders (In Vivo Metric, Healdsburg, CA, USA) were placed around each carotid artery and ultrasonic flow probes (Transonic Systems Inc., Ithaca, NY, USA) between the heart and occluders. To measure the fetal electrocorticogram (ECoG), two pairs of screws (Small Parts, Inc., Miami Lakes, FL, USA) were placed onto the dura with a reference electrode sewn to the scalp (Gunn et al., 1997) and connected to the recorder (ADInstruments, Colorado Springs, CO, USA) with insulated wires (Alpha Wire Co., Elizabeth, N.J., USA).

After recovery from surgery at 125-130 days of gestation, the ewes were assigned to four groups: instrumented non-ischemic sham-control treated (non-ischemic, $n=5$ ), 30-minutes of carotid occlusion, hereafter designated as ischemia, and 4-h reperfusion (I/R-4, n=5), ischemia and 24-h reperfusion (I/R-24, n=5), or ischemia and 48-h reperfusion (I/R-48, $\mathrm{n}=5$ ). To minimize unnecessary animal usage, three-instrumented non-ischemic control fetal 
sheep e.g. undergoing full surgical procedures but without carotid artery occlusion, exposed to 24-h of reperfusion and two-instrumented non-ischemic fetal sheep exposed to 48-h of reperfusion were studied. There were no differences in blood-brain barrier permeability or tight junction protein expression between the two control groups. Therefore, the nonischemic control animals were pooled for a total $n=5$. Full term gestation for the breed of sheep used in our study is 148 days of gestation according to the supplier (Purdue, Lafayette, IN). Thus, the fetal sheep were studied at approximately $85 \%$ of gestation in this study. Although the relative maturation of ovine and human brains cannot be precisely compared, the sheep brain at $80-85 \%$ of gestation is generally thought to be similar to the near term human infant (Gunn et al., 1997).

Thirty-minutes of ischemia was induced by inflating the occluders. At the conclusion of ischemia, the occluders were deflated and reperfusion continued for 4-, 24-, or 48-h. Study of blood-brain barrier permeability was performed over 1-h in each group at the conclusion of reperfusion. The ewe and fetus were then euthanized by intravenous pentobarbital (100$200 \mathrm{mg} / \mathrm{kg}$ ). The fetus was weighed, sex determined, and the brain quickly removed and weighed. One-half of the fetal brain was dissected for regional blood-brain barrier permeability analysis as previously described (Stonestreet et al., 1996), and the remainder frozen for tight junction protein expression analysis.

\section{Analytic Methods}

Blood-brain barrier function was measured with $a-\left[{ }^{14} \mathrm{C}\right]$-aminoisobutyric acid (AIB, 103 Da, American Radiolabeled Chemicals, Inc. St. Louis, MO, USA) as previously described in detail (Stonestreet et al., 1996). Briefly, $a-\left[{ }^{14} \mathrm{C}\right]-\mathrm{AIB}(27.6 \pm 5.7 \mu \mathrm{Ci} / \mathrm{kg}$, mean $\pm \mathrm{SD})$ was rapidly injected intravenously and arterial plasma $a-\left[{ }^{14} \mathrm{C}\right]$-AIB concentrations obtained at intervals both before and after injection.

Brain vascular volume was determined by administering technetium- $99^{\mathrm{m}}-\left({ }^{99 \mathrm{~m}} \mathrm{Tc}\right)$ radiolabeled red blood cells (RBCs) to the fetus two minutes before the end of the studies (Stonestreet et al., 1989a, Stonestreet et al., 1996). Four ml of whole blood obtained from the ewe was drawn into a syringe containing $0.8 \mathrm{ml}$ of acid citrated-dextrose, incubated with Tinpyrophosphate for 15 minutes, and with ${ }^{99 \mathrm{~m}} \mathrm{Tc}$ (Cardinal Health, RI) for an additional 15 minutes (Stonestreet et al., 1989a). The ${ }^{99 \mathrm{~m}}$ Tc-labeled RBCs were washed, resuspended in $0.154 \mathrm{M} \mathrm{NaCl}$ to a volume of $4 \mathrm{ml}$, and administered intravenously to the fetus. The radiolabeling efficiency of the RBCs exceeded $99 \%$. We used radiolabeled-RBCs in these studies rather than polyethylene glycol (Stonestreet et al., 1996) to avoid potential leakage of the small molecular weight substances from the brain vasculature after ischemia.

Fetal brains were dissected into the following regions: cerebral cortex (frontal, parietal, and occipital), white matter, caudate nucleus, hippocampus, cerebellum, thalamus, superior colliculus, inferior colliculus, pons, medulla, spinal cord, and pituitary gland. Plasma and tissue samples were prepared and radioactivity quantified for $\mathrm{a}-\left[{ }^{14} \mathrm{C}\right]$-AIB (Stonestreet et al., 1996). Knowledge of the plasma concentration profile and tracer concentration in the parenchyma allows calculation of the blood-to-brain transfer constant (Stonestreet et al., 1996):

$$
K_{i}\left(\mu \mathrm{l} \bullet \mathrm{g} \mathrm{Brain}^{-1} \bullet \min ^{-1}\right) \text { given by: } K_{i}=\mathrm{A}_{\mathrm{br}} /{ }_{\mathrm{o}}^{\mathrm{t}} \mathrm{c}_{\mathrm{p}}(T) \mathrm{d} T
$$

Where $\mathrm{A}_{\mathrm{br}}$ is the amount of tracer that crossed the blood-brain barrier from blood to brain during the tracer study $\left(\mathrm{dpm} \mathrm{g}^{-1}\right)$, and $\mathrm{c}_{\mathrm{p}}$ is the tracer concentration in plasma $\left(\mathrm{dpm} \bullet \mu \mathrm{l}^{-1}\right)$ at the time $\mathrm{t}(\mathrm{min})$. $\mathrm{A}_{\mathrm{br}}$ is obtained by correcting the total amount of isotope measured in the 
tissue $A_{m}\left(\mathrm{dpm}^{\circ} \mathrm{g}^{-1}\right)$ for the residual part remaining in the brain vasculature space, which is measured by ${ }^{99 m}$ Tc-labeled RBCs. Thus, $A_{b r}=A_{m}-V_{p} c_{p}$, where $V_{p}$ is the blood volume of brain tissue $\left(\mu l \cdot \mathrm{g}^{-1}\right)$ and $\mathrm{c}_{\mathrm{p}}$ is the concentration of tracer in the terminal plasma sample $\left(\mathrm{dpm} \bullet \mathrm{g}^{-1}\right) \cdot \mathrm{V}_{\mathrm{p}}=\mathrm{A}_{\mathrm{m}}^{\dagger} / \mathrm{c}_{\mathrm{p}}^{\dagger}$, where $\mathrm{A} \dagger \mathrm{m}$ and $\mathrm{c}_{\mathrm{p}}^{\dagger}$ have the same definitions as $\mathrm{A}_{\mathrm{m}}$ and $\mathrm{c}_{\mathrm{p}}$ above except that they apply to the ${ }^{99 \mathrm{~m}} \mathrm{Tc}$-labeled RBCs (Stonestreet et al., 1996)

Fetal arterial blood gases, $\mathrm{pH}$, heart rate, arterial blood pressure (MABP) hematocrit, lactate, and osmolarity values were measured at baseline, and sequentially after the end of ischemia. ECoG and carotid arterial blood flow were obtained at baseline, and during and after ischemia. Blood gases and $\mathrm{pH}$ were measured on a blood gas analyzer (model 248, Siemens, Washington, DC) corrected to $39.5^{\circ} \mathrm{C}$ for fetuses and $38.5^{\circ} \mathrm{C}$ for ewes. The ECoG was amplified, filtered, and recorded on a PowerLab Data Acquisition System (ADInstruments, Colorado Springs, CO). Carotid arterial blood flow was measured with the flow probes and recorded (Small Animal Blood Flow Meter: T206, Transonic Systems Inc. Ithaca, NY).

Although carotid blood flow does not directly measure brain blood flow, carotid arterial and brain blood flow are closely related (van Bel et al., 1994). Carotid arterial blood flow was the sum of left and right carotid arterial blood flow averaged over 5-minutes at each measurement time.

\section{ECoG Processing}

All ECoG files were visually inspected by a board certified epileptologist (J.G.), who was not aware of the group identity. The recorded ECoG signals were digitized (16 bits, 1000 $\mathrm{Hz}$ ) and stored. Signal processing was performed off line with MATLAB ${ }^{\circledR}$ (Mathworks, Natick, MA) on data segments from the baseline, ischemia, and reperfusion periods and during sham-control treatment, which were extracted from the ECoG recordings of each fetus. The duration of each ECoG segment averaged 15 minutes in each of the four groups. The length of the analyzed ECoG segments did not differ among the groups. We first analyzed the ECoG data to determine the frequency range that suggested the largest differences among the study periods i.e. baseline, ischemia, and reperfusion. The grand average power spectral densities (PSD) were used to estimate the frequency ranges. Preliminary examination of five sheep exposed to ischemia and reperfusion for 4-h suggested that a discriminatory frequency band of $10-100 \mathrm{~Hz}$ was optimal for subsequent analysis. Then, to calculate the power of the extracted data, segments in this band were subdivided into ten-second non-overlapping windows. A 10-sec window was selected based upon requirements for the window to be long enough for accurate power analysis estimates and short enough to eliminate potential artifacts. A fifth order Butterworth band pass filter of $10-100 \mathrm{~Hz}$ and a $60 \mathrm{~Hz}$ notch filter were applied to each window. The window mean was subtracted and the variance of the de-meaned windows used as the window power because the power of a sample with a zero mean is equal to the sample variance (Shiavi, 2007). The overall power of each segment was calculated as an average power for the windows within the segment that did not contain discontinuities caused by artifacts. The power of the segments was normalized to a zero mean and unit standard deviation for each fetus to account for offset power differences among the fetuses. Finally, the baseline power for each group was subtracted from the power for the rest of the segments before analysis.

\section{Protein Extraction}

Cell membrane fractions of the cerebral cortical, cerebellar, and hippocampal samples for occludin, claudin- 1 and claudin-5 protein analyses were extracted in Triton/Deoxycholate/ Sodium-dodecyl-sulfate $(100 \mathrm{mM} \mathrm{NaCl}, 1 \%$ Triton- $\mathrm{X}, 0.5$ sodium deoxycholate, $0.2 \%$ sodium-dodecyl-sulfate (SDS), $2 \mathrm{mM}$ EDTA, and $1 \mathrm{mM}$ benzamidine) with $1 \%$ complete protease inhibitor cocktail (Roche, Nutley, NJ). The cytosolic cell fraction for ZO-1 and ZO-2 was extracted in urea buffer $\left(6 \mathrm{M}\right.$ urea, $150 \mathrm{mM} \mathrm{NaCl}, 5 \mathrm{mM} \mathrm{MgCl}_{2}, 5 \mathrm{mM}$ EGTA, 
$10 \mathrm{mM}$ Tris, $\mathrm{pH} 8.0$, and $1 \%$ Triton-X) with $1 \%$ complete protease inhibitor cocktail. Total protein concentrations of the homogenates were determined with a bicinchoninic acid protein assay (BCA, Pierce, Rockford, IL).

\section{Western Immunoblot Detection and Quantification of Proteins}

Fifty $\mu \mathrm{g}$ of total protein per well were fractionated by SDS-PAGE electrophoresis and transferred onto PVDF membranes (0.2 micron, Bio-Rad Laboratories, Hercules, CA) using a semi-dry technique. Membranes were incubated with primary antibodies: mouse occludin monoclonal antibody (mAb, Zymed, San Francisco, CA) at a dilution of 1:2500; mouse claudin-1 mAb (Zymed) at a dilution of 1:6000; mouse claudin-5 and ZO-1 mAbs (Zymed) at a dilution of 1:5000 and mouse glyceraldehyde-3-phosphate dehydrogenase (GAPDH) mAb (Imgenex, San Diego, CA) at a dilution of 1:5000; and rabbit ZO-2 polyclonal antibody (Zymed) at a dilution of 1:5000. Peroxidase-labeled secondary antibodies were used: goat anti-mouse secondary antibodies (Zymed) at dilution of 1:5000 for occludin, 1:10,000 for claudin-1, claudin-5, ZO-1 and GAPDH, and goat anti-rabbit secondary antibody (Zymed) at a dilution of 1:10,000 for ZO-2.

All experimental samples were normalized to a reference protein standard that was obtained from a homogenate protein pool from the cerebral cortex of a single adult sheep. As we previously described, these samples served as an internal control reference standard for quality control of loading, transfer, verification of potential internal variability across the gels, and for normalization of cerebral cortical, cerebellar and hippocampal densitometric values to permit accurate comparisons against a single internal control standard among the different groups and immunoblots (Malaeb et al., 2007). The same internal control sample was used for each tight junction protein on all immunoblots, thereby minimizing potential differences among immunoblots due to loading, transfer, and autoradiographic densitometric measurements. The experimental tight junction protein densitometrical values were expressed as a ratio to the internal control samples, facilitating normalized comparisons among the different groups and immunoblots. In addition, GAPDH expression was also used as a loading control to ensure that equal amounts of protein had been applied to each lane. However, the experimental protein bands were not normalized to the GAPDH, rather as described above and previously (Kim et al., 2006, Malaeb et al., 2007), the experimental protein bands were normalized to the internal control samples to facilitate comparisons among the multiple immunoblots for the 20 control and experimental subjects in the current study.

Each immunoblot included samples from the four groups and three internal control samples. The internal control samples were included in three lanes, as the first, middle, and last samples on each immunoblot. A coefficient of variation for the internal control samples on each immunoblot was calculated. The values for the experimental samples were considered valid only if the percent coefficient of variation for the internal control samples was less than $20 \%$ on each immunoblot. We have previously shown that this method correlates with values that were normalized as ratios to $\beta$-actin (Kim et al., 2006) and have published this procedure extensively (Kim et al., 2006, Malaeb et al., 2007). The extracts from the cerebral cortex, cerebellum, and hippocampus from 20 fetal sheep were placed on different immunoblots. Therefore, to facilitate graphic clarity in Fig. 3 and 4, we selected the immunoblot that most closely represented the mean values for each group.

We also examined the relative expression of each tight junction protein among the cerebral cortical, hippocampal and cerebellar brain regions within the non-ischemic group to determine if there were any differences in protein expression among these brain regions under basal conditions as we have previously described (Sadowska et al., 2009). 
Madin-Darby canine kidney cell lysate (MDCK, Canine Kidney Carcinoma, BD

Biosciences, San Diego, CA) was used as a positive control for occludin, claudin-1, and ZO-1 and ZO-2, and rat lung for claudin-5 (Malaeb et al., 2007). Positive controls were used on the same immunoblot as sheep brain samples to establish that the tight junction proteins identified by the antibodies were the same as the known protein for which the antibodies were specific. Detection of occludin, claudin-1, claudin-5, ZO-1, and ZO-2 bands at 65, 22 , 22,225 , and $160 \mathrm{kDa}$, respectively, was dependent on incubation with primary antibody, omission of which resulted in the absence of this signal.

\section{Densitometric Analysis}

Band intensities were analyzed with a Gel-Pro Analyzer (Media Cybernetics, Silver Spring, MD, USA). Experimental samples were normalized to the average of the three respective internal control samples on each immunoblot. The final values for each protein in each brain region represented an average of the densitometry values from at least two different immunoblots (range 2-6) and were presented as a ratio to the internal control sample.

\section{Statistical Analysis}

Results are expressed as mean \pm standard deviation (SD), with the exception of the ECoG, which are expressed as median $\pm \mathrm{SD}$. The median for the ECoG was used due to the larger effect of movement on the mean. Two-factor analysis of variance (ANOVA) was used to compare ECoG recordings from the ischemia and reperfusion study periods that were normalized to the baseline ECoG values between the sham-control and ischemic-reperfusion groups. In view of the fact that all the animals were subjected to $30 \mathrm{~min}$ ischemia, data from I/R-4, I/R-24 and IR-48 groups were pooled into one I/R group for analysis and graphic presentation of ECoG and carotid blood flow. Repeated measures two-factor ANOVA was used to compare carotid blood flow and regional blood-brain barrier permeability within and between the groups. One-way ANOVAs were used to detect differences among the three brain regions for each tight junction protein examined. If a significant difference was found by ANOVA, the Fisher LSD test was used to detect specific differences among the study groups and brain regions. Stepwise multiple regression analysis was used to compare associations between changes in blood-brain barrier permeability and tight junction protein expression under the different reperfusion duration conditions. Because the non-ischemic and ischemia-reperfusion groups received different treatments, these different categorical variables were accounted for by applying a dummy coding variable in the multiple regression analyses (Pedharzur, 1973, Stonestreet et al., 1989b). A value of $P<0.05$ was considered statistically significant.

\section{RESULTS}

Differences in gestational age ( $F=0.60, P=0.62)$, brain weight $(F=0.83, P=0.50)$, or body weight $(F=0.59, P=0.63)$ were not observed among the non-ischemic, I/R-4, I/R-24, and I/ $\mathrm{R}$-48 groups (Table 1). The arterial $\mathrm{pH}, \mathrm{PO}_{2}$ and $\mathrm{PCO}_{2}$, heart rate, MABP, lactate, hematocrit, and osmolarity values were within the normal physiologic range for our laboratory (Stonestreet et al., 1993), and did not change during the study periods within or between groups (Table 2).

\section{ECoG and Carotid Blood Flow}

The ECoG analysis and carotid blood flow values were determined to verify that ischemic exposure was adequate in the fetuses, regardless of the differences in duration of reperfusion. This was confirmed by ECoG attenuation and carotid blood flow values approaching zero during ischemia (Fig. 1A and B). On visual inspection of the ECoG signals (J.G.), the three I/R groups demonstrated similar attenuations of greater than $50 \%$ 
from the baseline amplitude values during ischemia, whereas the non-ischemic fetuses did not exhibit any amplitude attenuation during sham treatment $(F=0.54, P=0.49$, Data not shown). The grand average power spectral density (PSD-ECoG) signals demonstrated significant reductions from baseline values during ischemia $(F=26.26, P<0.05$, Fig. 1A). However, after ischemia, the ECoG values returned to values that were similar to baseline values and did not differ between non-ischemic and ischemia-reperfusion groups $(F=1.28$, $P=0.31$ ). The carotid arterial blood flow values approached zero within one minute after the onset of ischemia, and remained in this range for the 30-minutes duration of ischemia and also returned to values that did not differ from baseline after ischemia (Fig. 1B).

\section{Blood-Brain Barrier Permeability $\left(\mathrm{K}_{\mathrm{i}}\right)$ Measurements}

The $K_{i}$ values were significantly higher across brain regions in fetuses of the I/R-4, I/R-24, and I/R-48 groups than in the non-ischemic group indicating that reperfusion for 4-, 24- and 48 -h resulted in increases in blood-brain barrier permeability (F=10.6, $P<0.05$, Fig. 2). The $K_{i}$ values were also higher across brain regions in fetuses of the I/R-4 group than in the I/ $\mathrm{R}-24(\mathrm{~F}=10.2, P<0.05)$ and $\mathrm{I} / \mathrm{R}-48(\mathrm{~F}=6.1, P<0.05)$ groups suggesting that the $K_{i}$ values were highest at 4-h after ischemia. There were no differences across brain regions between the I/R-24 and I/R-48 groups, suggesting that the increases in $K_{i}$ values were similar at 24and 48-h after ischemia $(\mathrm{F}=0.5, P=0.5)$. The sex of the fetuses did not influence the $K_{i}$ values as a function of length of reperfusion $(\mathrm{F}=0.07, P=0.80)$.

The magnitude of the increases in permeability after ischemia was not uniform across brain regions within the I/R-4 (F=16.6, $P<0.05), \mathrm{I} / \mathrm{R}-24(\mathrm{~F}=22.5, P<0.05)$ and $\mathrm{I} / \mathrm{R}-48(\mathrm{~F}=14.6$, $P<0.05$ ) groups (Fig. 2) suggesting that there was a heterogeneity in the responses among different brain regions to ischemia-reperfusion. Inspection of Fig. 2 suggests that the largest increases appear in the caudal brain structures including cerebellum, inferior colliculus, pons, medulla, and spinal cord.

The $K_{i}$ values were also higher across the cerebral cortical regions in fetuses in the I/R-4, I/ $\mathrm{R}-24$, and I/R-48 groups than in the non-ischemic group (F=11.8, $P<0.05$, Fig. 3). The $K_{i}$ values were higher in the parietal and occipital cortices of the I/R-4 group $(P<0.05)$ and in the occipital cortex of the I/R-48 $(P<0.05)$ group than in the non-ischemic group.

The pituitary gland is an intracranial structure lacking a blood-brain barrier (Stonestreet et al., 1996). Consistent with our previous work (Stonestreet et al., 1996), $K_{i}$ values in the pituitary gland were much higher than in other intracranial structures $(20.7 \pm 4.21,28.6 \pm 5.69$, 28.8 \pm 2.96 , and 25.8 $\pm 7.42 \mu \mathrm{l} \bullet \mathrm{g} \mathrm{Brain}{ }^{-1} \bullet \mathrm{min}^{-1}$ in non-ischemic, I/R-4, I/R-24, and I/R-48 groups, respectively). The considerably higher permeability in this structure compared with other brain regions further validates the $K_{i}$ values as measures of blood-brain barrier permeability in brain regions known to possess tight blood-brain barrier properties. The pituitary gland $K_{i}$ values were higher in the fetuses of the I/R-4, I/R-24, and I/R-48 groups than in the non-ischemic group $(\mathrm{F}=7.41, P<0.05)$ suggesting that even though the pituitary gland lacks a tight blood-brain barrier, its permeability still increases after ischemicreperfusion injury.

\section{Blood Volume Measurements}

Table 3 contains the blood volume values in the brain regions of all groups. Blood volume was higher in the cerebral cortex of the I/R-24 group than in the non-ischemic and I/R-4 groups, and in the $\mathrm{I} / \mathrm{R}-48$ group than in the $\mathrm{I} / \mathrm{R}-4$ group $(\mathrm{F}=3.37, P<0.05)$. Regional blood volume was higher in white matter of the I/R-24 group than in the non-ischemic and I/R-48 groups $(\mathrm{F}=3.29, P<0.05)$, and in the cerebellum of $\mathrm{I} / \mathrm{R}-24$ and $\mathrm{I} / \mathrm{R}-48$ groups than in $\mathrm{I} / \mathrm{R}-4$ group $(\mathrm{F}=5.71, P<0.01)$. Differences were not observed in the blood volume of other brain 
regions among the groups (caudate nucleus: $F=1.96, P=0.16$; hippocampus: $F=2.96, P=0.06$; inferior colliculus: $F=0.74, P=0.54$; medulla: $F=2.88, P=0.07$; pons: $F=1.17, P=0.35$; superior colliculus: $F=1.37, P=0.29$; spinal cord: $F=1.21, P=0.34$; thalamus: $F=0.88$, $P=0.47$ ). Therefore, ischemic-reperfusion-related brain injury is associated with a relatively limited number of changes in regional blood volume in fetal brain. As expected, the blood volume values measured with RBCs were slightly lower than plasma volumes measured with polyethylene glycol, molecular weight=4000 (Stonestreet et al., 1996).

\section{Tight Junction Protein Expression}

Occludin expression was lower $(P<0.05)$ in cerebral cortex $(\mathrm{F}=5.1)$, hippocampus $(\mathrm{F}=3.5)$, and cerebellum ( $\mathrm{F}=3.4)$ of the $\mathrm{I} / \mathrm{R}-4$ group than in the non-ischemic group, higher $(P<0.05)$ in these regions in the I/R-24 group than in the I/R-4 group, and higher $(P<0.05)$ in the cerebral cortex and cerebellum of the I/R-48 group than in the I/R-4 group (Fig. 4 A). In contrast, claudin 1 expression was higher in the hippocampus $(\mathrm{F}=4.4, P<0.05)$ of the $\mathrm{I} / \mathrm{R}-24$ and $\mathrm{I} / \mathrm{R}-48$ groups than in the non-ischemic group, and in the cerebellum $(\mathrm{F}=19.4, P<0.05)$ of the I/R-4 group than in the non-ischemic group, lower $(P<0.05)$ in the cerebellum of the I/ R-24 and I/R-48 groups than in the I/R-4 group, and did not differ in the cerebral cortex $(\mathrm{F}=0.20, P=0.86$ ) among groups (Fig. $4 \mathrm{~B})$. Claudin-5 expression was lower $(P<0.05)$ in cerebral cortex $(\mathrm{F}=4.0)$, hippocampus $(\mathrm{F}=6.28)$, and cerebellum $(\mathrm{F}=3.6)$ of the $\mathrm{I} / \mathrm{R}-4$ group than in the non-ischemic group, and higher $(P<0.05)$ in these regions of the $\mathrm{I} / \mathrm{R}-24$ than $\mathrm{I} /$ R-4 group, but did not differ between the I/R-48 and I/R-4 groups (Fig. 4 C). Therefore, occludin and claudin-5 expression were lower in the I/R-4 group than in the non-ischemic group, but tended to return toward values similar to the non-ischemic group by $24-$ and $48-\mathrm{h}$ after ischemia.

ZO-1 is expressed as two isoforms due to alternative RNA splicing (Kurihara et al., 1992). Although we identified two ZO-1 protein bands in some brain regions, the densitometry values for the two bands were not distinct enough in all of the groups to permit accurate analysis of the separate bands. Hence, the densitometry values of the two ZO-1 bands were combined for analysis. Likewise, the multiple bands of ZO-2 were combined. ZO-1 and $\mathrm{ZO}-2$ expression were lower in cerebral cortex, hippocampus, and cerebellum of the I/R-4, I/ $\mathrm{R}-24$ and $\mathrm{I} / \mathrm{R}-48$ groups than in the non-ischemic group (ZO-1: $\mathrm{F}=5.8, \mathrm{~F}=14.3$, and $\mathrm{F}=24.0$, $P<0.05 ; \mathrm{ZO}-2: \mathrm{F}=3.3, F=3.7$, and $\mathrm{F}=6.2, P<0.05$, in the cerebral cortex, hippocampus, and cerebellum, respectively; Fig. 5 A and B). Differences in ZO-1 and ZO-2 expression were not observed among the I/R-4, I/R-24, and I/R-48 groups (ZO-1: $F=1.17, F=3.19$, and $F=1.72, P>0.05$; ZO-2: $F=0.20, F=0.04$, and $F=1.19, P>0.05$, in the cerebral cortex, hippocampus, and cerebellum, respectively).

We also examined the relative expression of each tight junction protein in the cerebral cortex, hippocampus, and cerebellum within the non-ischemic group to determine if there were any differences in tight junction protein expression among these brain regions under basal conditions (Sadowska et al., 2009). Occludin, claudin-5, ZO-1, and ZO-2 expression was higher in the cerebellum than the cerebral cortex and hippocampus $(F=92.4, F=22.1$, $F=487.8$, and $F=99.7, P<0.05$ for occludin, claudin-5, ZO-1, and ZO-2, respectively, Fig. 4 and 5). In contrast, claudin-1 expression was lower in the cerebellum than cerebral cortex and hippocampus $(F=56.1, P<0.05$, Fig. 4$)$.

\section{Correlational Analysis between Regional Blood-Brain Barrier Permeability and Tight Junction Proteins}

The $K_{i}$ values demonstrated an inverse linear correlation with claudin-5 expression in the cerebral cortex (Fig. 6), with occludin, claudin-5, ZO-1 and ZO-2 in the hippocampus, and with ZO-1 or ZO-2 in the cerebellum (Table 4), but not with occludin, claudin-1, ZO-1 or 
ZO-2 in the cerebral cortex, claudin-1 in hippocampus, or occludin, claudin-1, or claudin-5 in the cerebellum. The inverse correlations between $K_{i}$ and tight junction proteins suggest that decreases in the tight junction proteins are associated with the increases in blood-brain barrier permeability.

\section{DISCUSSION}

The purpose of this study was to examine the effects of different durations of reperfusion after ischemic brain injury on blood-brain barrier function and tight junction protein expression in ovine fetuses. Although previous studies have investigated the time course of blood-brain barrier dysfunction after ischemia in adult subjects (Strbian et al., 2008), information regarding the structure and function of the blood-brain barrier in the immature brain is sparse, particularly under pathological conditions. There is no previous quantitative data measuring blood-brain barrier permeability $\left(K_{i}\right)$ after ischemia in the fetus, particularly not in the brain of a precocial species such as the sheep. Moreover, there are methodological discrepancies among studies of adult subjects, including differences in animal species, the use of a variety of different tracers, in tracer circulation times, lengths of ischemia, and durations of reperfusion (Kuroiwa et al., 1985, Belayev et al., 1996, Neumann-Haefelin et al., 2000, Strbian et al., 2008). In the current study, we achieved near complete cessation of carotid arterial blood flow for 30-minutes and documented attenuation of the ECoG amplitude, thereby establishing efficacy of the insult. Our findings are as follows. 1) Ischemia with reperfusion for 4-, 24-, or 48-h impaired blood-brain barrier function. 2) The largest increase in permeability occurred 4-h after ischemia. 3) The blood-brain barrier appears less permeable at 24- and 48-h after ischemia suggesting that barrier function improves relatively soon after injury. 4) Changes in the molecular composition of tight junctions are associated with increases in blood-brain barrier permeability after ischemia in the fetus. Impaired barrier function represents a major unappreciated component of hypoxicischemic brain injury in the fetus, particularly early after the insult, and thus could represent a potential therapeutic target.

The biochemical and hemodynamic values measured in our study did not differ from baseline values among or within the non-ischemic and ischemic-reperfusion groups. Carotid blood flow and ECoG did not differ from the baseline values in the fetuses of ischemicreperfusion groups after ischemia. Therefore, our findings suggest that prolonged intervals of reperfusion after ischemic brain injury may not have a major impact upon systemic biochemical, metabolic, and hemodynamic homeostasis in fetal sheep. We also documented small differences in blood volume values of some brain regions among groups (Table 3). However, these differences do not account for ischemia-reperfusion related permeability changes because they were modest, occurred only in a few brain regions, and the $K_{i}$ calculations account for the residual AIB remaining in the vascular space at the end of the studies (Stonestreet et al., 1996).

Our findings demonstrating the largest increase in permeability occurred 4-h after ischemia in fetal sheep, are consistent, in part, with findings in adult rats after traumatic brain injury (Baskaya et al., 1997). A biphasic pattern of blood-brain barrier opening has been reported in adult rodents (Belayev et al., 1996, Baskaya et al., 1997, Huang et al., 1999). Early opening occurs between 25-minutes (Strbian et al., 2008) and 6-h (Baskaya et al., 1997, Dimitrijevic et al., 2006) after ischemia, with a second delayed barrier opening between 5and 72-h (Kuroiwa et al., 1985), between 22- and 46-h (Huang et al., 1999), and at 24-h (Dimitrijevic et al., 2006), 48-h (Belayev et al., 1996, Rosenberg et al., 1998), and 72-h (Jiao et al., 2011) after ischemia in adult rodents. However, we did not observe this pattern in our fetal sheep. Although blood-brain barrier permeability was lower at 24- and 48- than at 4-h, values were not similar to the non-ischemic group. However, we speculate that the 
decreased barrier permeability at 24- and 48-h compared with 4-h of reperfusion suggests partial restitution of barrier function could begin relatively soon after an ischemic insult in the fetus.

The response to ischemia-reperfusion was not homogenous among all brain regions. Similar to our previous findings (Stonestreet et al., 1996), inspection of regional permeability suggests that the permeability in all study groups was heterogeneous, and more pronounced in the caudal than rostral brain regions (Fig. 2). This observation could be in part attributable to increased permeability of the circumventricular organs in more caudal brain regions (Morita and Miyata, 2012). Some of these regions are also more vulnerable to hyperosmolar stress during development (Stonestreet et al., 2006). Hence, it appears that there could be an increased susceptibility of specific brain regions to ischemia-reperfusion in the immature brain.

The mechanism(s) responsible for blood-brain barrier dysfunction after ischemic injury have not been completely elucidated and could involve all components of the neurovascular unit (Abbott, 2000). Armstead et al., reported that the activated oxygen generation contributes to increased barrier permeability after ischemia/reperfusion in newborn pigs and that oxygen free radical scavengers partially attenuate the increased permeability associated with ischemia/reperfusion (Armstead et al., 1992). In addition, tight junction proteins are known to restrict movement of substances through paracellular pathways between adjacent endothelial cells (Hawkins and Davis, 2005) and ischemic-reperfusion injury is known to induce opening, cellular redistribution, and alterations in tight junction protein expression (Cipolla et al., 2004). We found significant differences in the response of transmembrane and associated cytoplasmic proteins to different durations of reperfusion. Overall, expression patterns of occludin and claudin-5 were similar, showing a decrease 4-h after ischemia and a return to values similar to those in the non-ischemic group by $24-$ and $48-\mathrm{h}$ after ischemia. Our findings are consistent with results in adult rodents examining the effects of 3-h of reperfusion after 90-minutes of MCAO (Yang et al., 2007) and 3-h of reperfusion after 2-h of MCAO on occludin and claudin-5 expression in microvascular endothelial cells (Jiao et al., 2011), but differ from results in which occludin and claudin-5 expression decreased between 3- and 120-h after ischemia (Jiao et al., 2011). Likewise, the decreased ZO-1 and ZO-2 expression 4-, 24-, and 48-h after ischemia are consistent with findings in adult rodents, in which ZO-1 expression decreased between 3- and 120-h after 2-h of MCAO (Jiao et al., 2011). Moreover, we have shown that 72-h after the same insult, claudin-5 expression actually increased, whereas ZO- 1 and ZO- 2 remained reduced in the cerebral cortex of fetal sheep (Malaeb et al., 2007). Taken together, our results suggest that restitution of occludin and claudin-5 expression begins relatively soon after ischemia and represents a continuum to increased expression 72-h after ischemia. However, the cytoplasmic associated proteins, ZO-1, and ZO-2, remain reduced for 72-h after ischemia in the fetal sheep brain.

In contrast, claudin-1 exhibited a very different expression pattern after ischemia. Similar to findings after hypoxia-reoxygenation (Mark and Davis, 2002), claudin-1 expression remained similar to the non-ischemic group in cerebral cortex, but increased 24- and 48-h after ischemia in hippocampus, and 4-h after ischemia in cerebellum. Although the higher claudin-1 expression after ischemia was not expected, it has recently been reported that blood-brain barrier leakiness was reduced around vessels expressing claudin-1 in a model of experimental autoimmune encephalomyelitis (Pfeiffer et al., 2011). Hence, the higher claudin-1 expression that we observed could potentially support the partial improvement of blood-brain barrier function observed in the hippocampus 24- and 48-h after ischemia (Fig. 2 and 3), but does not explain the higher permeability and claudin-1 expression in the cerebellum 4-h after ischemia. Thus, the response of the tight junction proteins to ischemia- 
reperfusion insult varies with respect to the specific protein, brain region, and duration of reperfusion.

It is also important to point out that the changes in the tight junction proteins occurred relatively rapidly after ischemia. The mechanisms underlying these changes cannot be discerned by our study but could involve multiple factors including the selective loss of certain proteins, suggesting rapid degradation, or could result from overall damage to endothelial cells, and/or interactions with other components of the neurovascular unit such as astrocytes and basement membranes (Abbott, 2000). Alternatively, other binding proteins could sequester tight junction proteins immediately after ischemia, and later release them.

Furthermore, we found increases in blood-brain barrier permeability were associated with decreases in claudin-5 expression in cerebral cortex and hippocampus, decreases in occludin in hippocampus, and decreases in ZO-1 and ZO-2 in hippocampus and cerebellum (Fig. 6; Table 4). Therefore, decreases in tight junction protein expression in the fetal brain after ischemia could have functional consequences. These findings are important as claudin-5 forms the primary "seal" of the tight junction restricting transfer of low molecular weight molecules from blood to brain (Honda et al., 2006), and occludin acts as a support molecule modulating tight junction function (Hawkins and Davis, 2005). The inverse linear correlations between increases in permeability and decreases in ZO-1 and ZO-2 protein expression in the hippocampus and cerebellum are consistent with previous studies of hypoxia-induced increases in paracellular permeability and decreases in ZO-1 and ZO-2 expression (Mark and Davis, 2002, Fischer et al., 2004). The continued reductions in ZO-1 and ZO-2 expression up to 72-h (Malaeb et al., 2007) after ischemia could contribute to persistently impaired barrier function because $\mathrm{ZO}-1$ and $\mathrm{ZO}-2$ are scaffolding proteins providing the structural basis for coupling transmembrane tight junction proteins to the cytoskeleton (Hawkins and Davis, 2005, Jiao et al., 2011). Consistent with our findings Lenzser et al. reported, the loss of occludin protein correlated well with increased barrier permeability $48 \mathrm{~h}$ after ischemia in adult rats (Lenzser et al., 2007). Moreover, loss of occludin protein was accompanied by the presence of lower molecular weight degradative proteins on Western immunoblot, and the increase in this low molecular weight protein correlated with the loss of occludin protein (Lenzser et al., 2007).

There are several limitations to our study. We were only able to examine a limited number of animals per group in this large mammalian species and determined permeability at a three time points after ischemia. Hence, we cannot comment upon potential changes in permeability between 4 and $24 \mathrm{~h}$ after ischemia, nor can we comment upon the long-term recovery after ischemia.

\section{CONCLUSIONS}

Impaired blood-brain barrier function is an important component of hypoxic-ischemic injury, particularly early after insults to the fetal brain. Ischemia/reperfusion of a specific duration results in variable changes in the levels of tight junction proteins that may be associated with changes in blood-brain barrier permeability. Changes in the molecular composition of tight junction proteins are associated with increases in barrier permeability after ischemia in the fetal brain and could represent a potential therapeutic target for the treatment of hypoxia-ischemia. Contributions of blood-brain barrier abnormalities to hypoxic-ischemic brain injury have not been fully appreciated in the fetus. Barrier dysfunction, particularly early after an insult, could potentially exacerbate brain damage by facilitating the entry of blood borne substances into the brain. 


\section{Acknowledgments}

We also would like to acknowledge the excellent editorial assistance of Courtney A. Hill, Ph.D.

\section{GRANTS}

Research reported in this publication was supported by the National Institute of General Medical Sciences of the National Institutes of Health under award number 1R01-HD-057100 and RI-INBRE P20RR016457-11. The content is solely the responsibility of the authors and does not necessarily represent the official views of the National Institutes of Health.

\section{REFERENCES}

Abbott NJ. Inflammatory Mediators and Modulation of Blood-Brain Barrier Permeability. Cellular and Molecular Neurobiology. 2000; 20:131-147. [PubMed: 10696506]

Armstead WM, Mirro R, Thelin OP, Shibata M, Zuckerman SL, Shanklin DR, Busija DW, Leffler $\mathrm{CW}$. Polyethylene glycol superoxide dismutase and catalase attenuate increased blood-brain barrier permeability after ischemia in piglets. Stroke. 1992; 23:755-762. [PubMed: 1579974]

Baskaya MK, Rao AM, Dogan A, Donaldson D, Dempsey RJ. The biphasic opening of the blood-brain barrier in the cortex and hippocampus after traumatic brain injury in rats. Neurosci Lett. 1997; 226:33-36. [PubMed: 9153635]

Belayev L, Busto R, Zhao W, Ginsberg MD. Quantitative evaluation of blood-brain barrier permeability following middle cerebral artery occlusion in rats. Brain Res. 1996; 739:88-96. [PubMed: 8955928]

Betz AL. An overview of the multiple functions of the blood-brain barrier. NIDA Res Monogr. 1992; 120:54-72. [PubMed: 1501692]

Betz AL, Goldstein GW. Specialized properties and solute transport in brain capillaries. Annu Rev Physiol. 1986; 48:241-250. [PubMed: 2871806]

Cipolla MJ, Crete R, Vitullo L, Rix RD. Transcellular transport as a mechanism of blood-brain barrier disruption during stroke. Front Biosci. 2004; 9:777-785. [PubMed: 14766407]

Dimitrijevic OB, Stamatovic SM, Keep RF, Andjelkovic AV. Effects of the chemokine CCL2 on blood-brain barrier permeability during ischemia-reperfusion injury. J Cereb Blood Flow Metab. 2006; 26:797-810. [PubMed: 16192992]

Fan X, Heijnen CJ, van der Kooij MA, Groenendaal F, van Bel F. The role and regulation of hypoxiainducible factor-1alpha expression in brain development and neonatal hypoxic-ischemic brain injury. Brain Res Rev. 2009; 62:99-108. [PubMed: 19786048]

Fischer S, Wiesnet M, Marti HH, Renz D, Schaper W. Simultaneous activation of several second messengers in hypoxia-induced hyperpermeability of brain derived endothelial cells. J Cell Physiol. 2004; 198:359-369. [PubMed: 14755541]

Gunn AJ, Gunn TR, de Haan HH, Williams CE, Gluckman PD. Dramatic neuronal rescue with prolonged selective head cooling after ischemia in fetal lambs. The Journal of Clinical Investigation. 1997; 99:248-256. [PubMed: 9005993]

Hawkins BT, Davis TP. The blood-brain barrier/neurovascular unit in health and disease. Pharmacol Rev. 2005; 57:173-185. [PubMed: 15914466]

Honda M, Nakagawa S, Hayashi K, Kitagawa N, Tsutsumi K, Nagata I, Niwa M. Adrenomedullin improves the blood-brain barrier function through the expression of claudin-5. Cell Mol Neurobiol. 2006; 26:109-118. [PubMed: 16763778]

Huang ZG, Xue D, Preston E, Karbalai H, Buchan AM. Biphasic opening of the blood-brain barrier following transient focal ischemia: effects of hypothermia. Can J Neurol Sci. 1999; 26:298-304. [PubMed: 10563216]

Jiao H, Wang Z, Liu Y, Wang P, Xue Y. Specific role of tight junction proteins claudin-5, occludin, and ZO-1 of the blood-brain barrier in a focal cerebral ischemic insult. J Mol Neurosci. 2011; 44:130-139. [PubMed: 21318404]

Kim CR, Sadowska GB, Petersson KH, Merino M, Sysyn GD, Padbury JF, Stonestreet BS. Effects of postnatal steroids on $\mathrm{Na}+\mathrm{K}+$-ATPase activity and alpha1- and beta1-subunit protein expression in 
the cerebral cortex and renal cortex of newborn lambs. Reprod Fertil Dev. 2006; 18:413-423. [PubMed: 16737634]

Kurihara H, Anderson JM, Farquhar MG. Diversity among tight junctions in rat kidney: glomerular slit diaphragms and endothelial junctions express only one isoform of the tight junction protein $\mathrm{ZO}-1$. Proc Natl Acad Sci U S A. 1992; 89:7075-7079. [PubMed: 1496002]

Kuroiwa T, Ting P, Martinez H, Klatzo I. The biphasic opening of the blood-brain barrier to proteins following temporary middle cerebral artery occlusion. Acta Neuropathol. 1985; 68:122-129. [PubMed: 3907257]

Lenzser G, Kis B, Snipes JA, Gaspar T, Sandor P, Komjati K, Szabo C, Busija DW. Contribution of poly(ADP-ribose) polymerase to postischemic blood-brain barrier damage in rats. J Cereb Blood Flow Metab. 2007; 27:1318-1326. [PubMed: 17213862]

Leonardo CC, Pennypacker KR. Neuroinflammation and MMPs: potential therapeutic targets in neonatal hypoxic-ischemic injury. J Neuroinflammation. 2009; 6:13. [PubMed: 19368723]

Lou HC, Lassen NA, Tweed WA, Johnson G, Jones M, Palahniuk RJ. Pressure passive cerebral blood flow and breakdown of the blood-brain barrier in experimental fetal asphyxia. Acta Paediatr Scand. 1979; 68:57-63. [PubMed: 31759]

Malaeb SN, Sadowska GB, Stonestreet BS. Effects of maternal treatment with corticosteroids on tight junction protein expression in the cerebral cortex of the ovine fetus with and without exposure to in utero brain ischemia. Brain Res. 2007; 1160:11-19. [PubMed: 17583681]

Mark KS, Davis TP. Cerebral microvascular changes in permeability and tight junctions induced by hypoxia-reoxygenation. American Journal of Physiology - Heart and Circulatory Physiology. 2002; 282:H1485-H1494. [PubMed: 11893586]

Mirro R, Armstead WM, Busija DW, Leffler CW. Blood to brain transport after newborn cerebral ischemia/reperfusion injury. Proc Soc Exp Biol Med. 1991; 197:268-272. [PubMed: 2068119]

Morita S, Miyata S. Different vascular permeability between the sensory and secretory circumventricular organs of adult mouse brain. Cell Tissue Res. 2012; 349:589-603. [PubMed: 22584508]

Muramatsu K, Fukuda A, Togari H, Wada Y, Nishino H. Vulnerability to cerebral hypoxic-ischemic insult in neonatal but not in adult rats is in parallel with disruption of the blood-brain barrier. Stroke. 1997; 28:2281-2288. discussion 2288-2289. [PubMed: 9368577]

Neumann-Haefelin T, Kastrup A, de Crespigny A, Yenari MA, Ringer T, Sun GH, Moseley ME. Serial MRI after transient focal cerebral ischemia in rats: dynamics of tissue injury, blood-brain barrier damage, and edema formation. Stroke. 2000; 31:1965-1972. discussion 1972-1963. [PubMed: 10926965]

Pedharzur, EJ. Multiple regression in behavioral ressearch. New York: CBS College Publishing; 1973. Dummy, effect, and orthogonal coding of categorical variables; p. 271-333.

Petersson KH, Pinar H, Stopa EG, Faris RA, Sadowska GB, Hanumara RC, Stonestreet BS. White matter injury after cerebral ischemia in ovine fetuses. Pediatr Res. 2002; 51:768-776. [PubMed: 12032276]

Pfeiffer F, Schafer J, Lyck R, Makrides V, Brunner S, Schaeren-Wiemers N, Deutsch U, Engelhardt B. Claudin-1 induced sealing of blood-brain barrier tight junctions ameliorates chronic experimental autoimmune encephalomyelitis. Acta Neuropathol. 2011; 122:601-614. [PubMed: 21983942]

Rosenberg GA, Estrada EY, Dencoff JE. Matrix metalloproteinases and TIMPs are associated with blood-brain barrier opening after reperfusion in rat brain. Stroke. 1998; 29:2189-2195. [PubMed: 9756602]

Sadowska GB, Malaeb SN, Stonestreet BS. Maternal glucocorticoid exposure alters tight junction protein expression in the brain of fetal sheep. Am J Physiol Heart Circ Physiol. 2009; 298:H179H188. [PubMed: 19855054]

Shiavi, R. Introduction to applied statistical signal analysis: Guide to biomedical and electrical engineering applications. San Diego, Calif: Academic Press, Elsiver, Inc.; 2007. Random signals, linear systems, and power spectra; p. 201-205.

Stonestreet BS, Burgess GH, Cserr HF. Blood-brain barrier integrity and brain water and electrolytes during hypoxia/hypercapnia and hypotension in newborn piglets. Brain Res. 1992; 590:263-270. [PubMed: 1422834] 
Stonestreet BS, Goldstein M, Oh W, Widness JA. Effects of prolonged hyperinsulinemia on erythropoiesis in fetal sheep. Am J Physiol. 1989a; 257:R1199-R1204. [PubMed: 2511768]

Stonestreet BS, Le E, Berard DJ. Circulatory and metabolic effects of beta-adrenergic blockade in the hyperinsulinemic ovine fetus. Am J Physiol. 1993; 265:H1098-H1106. [PubMed: 7902002]

Stonestreet BS, Ogburn PL, Goldstein M, Oh W, Widness JA. Effects of chronic fetal hyperinsulinemia on plasma arachidonic acid and prostaglandin concentrations. Am J Obstet Gynecol. 1989b; 161:894-899. [PubMed: 2679106]

Stonestreet BS, Patlak CS, Pettigrew KD, Reilly CB, Cserr HF. Ontogeny of blood-brain barrier function in ovine fetuses, lambs, and adults. Am J Physiol. 1996; 271:R1594-R1601. [PubMed: 8997357]

Stonestreet BS, Sadowska GB, Leeman J, Hanumara RC, Petersson KH, Patlak CS. Effects of acute hyperosmolality on blood-brain barrier function in ovine fetuses and lambs. Am J Physiol Regul Integr Comp Physiol. 2006; 291:R1031-R1039. [PubMed: 16690764]

Strbian D, Durukan A, Pitkonen M, Marinkovic I, Tatlisumak E, Pedrono E, Abo-Ramadan U, Tatlisumak T. The blood-brain barrier is continuously open for several weeks following transient focal cerebral ischemia. Neuroscience. 2008; 153:175-181. [PubMed: 18367342]

Temesvari P, Kovacs J. Selective opening of the blood-brain barrier in newborn piglets with experimental pneumothorax. Neurosci Lett. 1988; 93:38-43. [PubMed: 3211368]

Tweed WA, Pash M, Doig G. Cerebrovascular mechanisms in perinatal asphyxia: the role of vasogenic brain edema. Pediatr Res. 1981; 15:44-46. [PubMed: 6894189]

Vaccarino FM, Ment LR. Injury and repair in developing brain. Arch Dis Child Fetal Neonatal Ed. 2004; 89:F190-F192. [PubMed: 15102716]

van Bel F, Roman C, Klautz RJ, Teitel DF, Rudolph AM. Relationship between brain blood flow and carotid arterial flow in the sheep fetus. Pediatr Res. 1994; 35:329-333. [PubMed: 8190521]

Vannucci RC. Mechanisms of perinatal hypoxic-ischemic brain damage. Semin Perinatol. 1993; 17:330-337. [PubMed: 8290975]

Yang Y, Estrada EY, Thompson JF, Liu W, Rosenberg GA. Matrix metalloproteinase-mediated disruption of tight junction proteins in cerebral vessels is reversed by synthetic matrix metalloproteinase inhibitor in focal ischemia in rat. J Cereb Blood Flow Metab. 2007; 27:697-709. [PubMed: 16850029] 
Blood-brain barrier permeability increases after ischemia-reperfusion in the fetus. Increases in permeability $\left(K_{i}\right)$ change as function of the duration of reperfusion. Tight junction (TJ) protein expression decreases after ischemia in fetal brain. TJ protein decreases are associated with ischemia-related increases in permeability. 
$\Lambda$ Non - Ischemic, $\square$ I/R groups
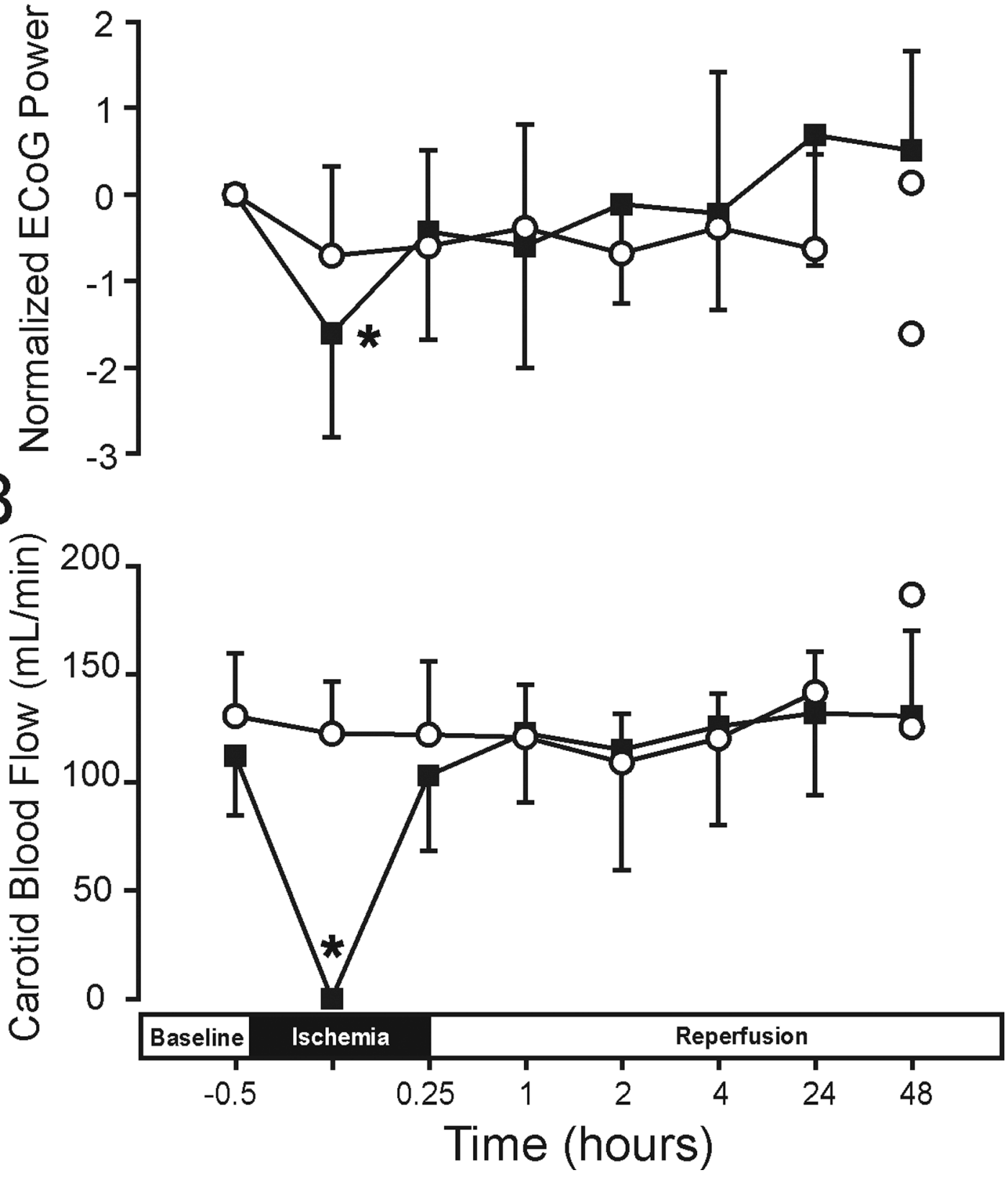

Figure 1.

ECoG (A) and carotid blood flow (B) plotted for the non-ischemic ( $\mathrm{n}=4$ up to $24-\mathrm{h}$ and $\mathrm{n}=2$ up to 48 -h because the ECoG in one animal at 24-h was not adequate, and $n=5$ up to 24-h and $\mathrm{n}=2$ up to 48 -h for ECoG and carotid blood flow, respectively), I/R group includes I/ $\mathrm{R}-4, \mathrm{n}=5, \mathrm{I} / \mathrm{R}-24 \mathrm{n}=5$, and I/R-48, n=5 plotted against study time in hours, before ischemia at baseline, and during ischemia and reperfusion. ECoG (A) Y-axis is the normalized ECoG power as difference from the individually averaged baseline ECoG values. Values are median \pm SD and mean \pm SD for ECoG and carotid arterial blood flow, respectively. When $\mathrm{n}=2$, values plotted as separate symbols rather than means. (A) $* P<0.05$ ischemia vs. 
baseline within I/R group, but not non-ischemic group and (B) $* P<0.05$ ischemia vs. baseline within $\mathrm{I} / \mathrm{R}$ group. 


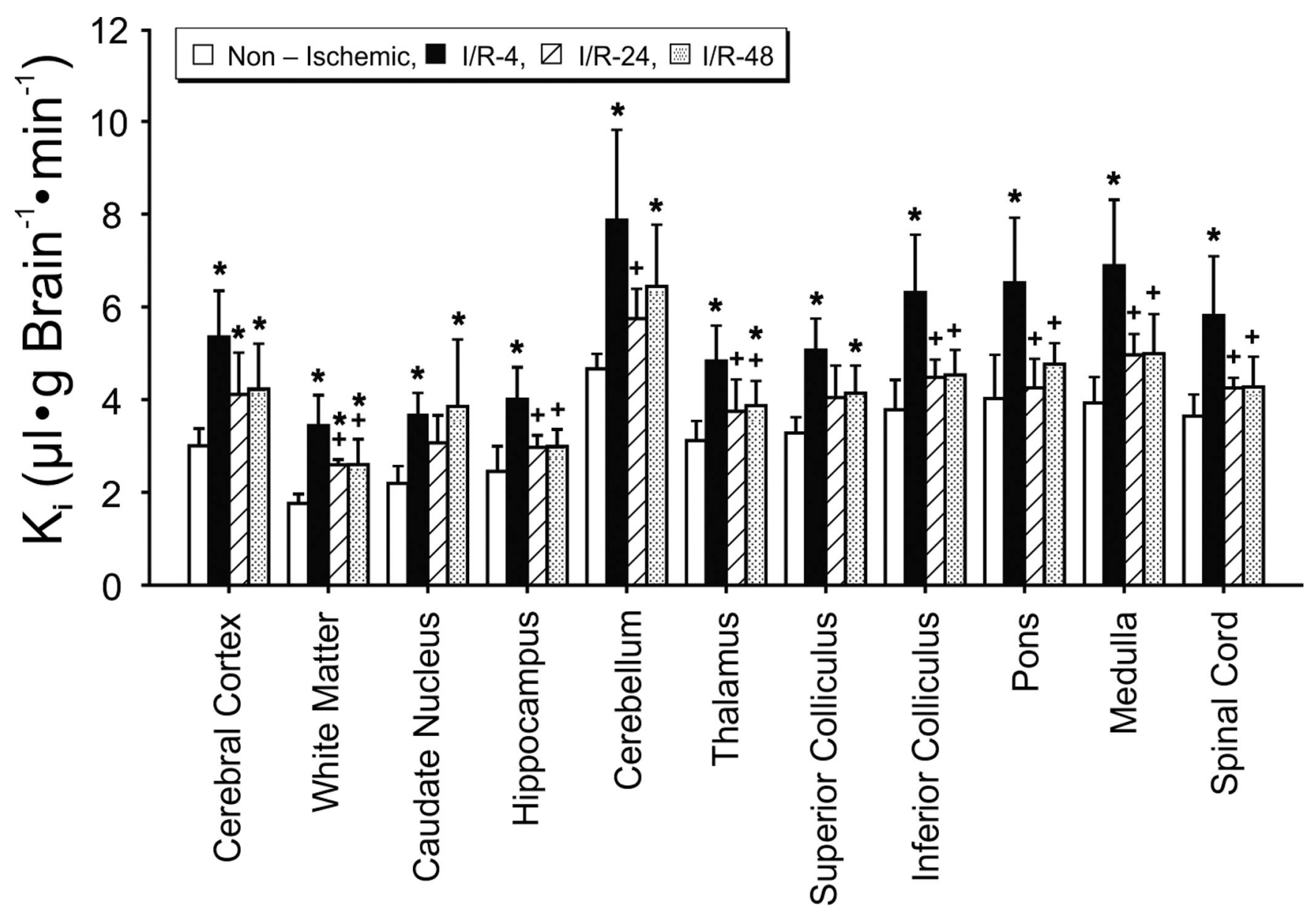

Figure 2.

Blood-to-brain transfer constants $\left(K_{i}\right)$ in the non-ischemic $(\mathrm{n}=5), \mathrm{I} / \mathrm{R}-4(\mathrm{n}=5), \mathrm{I} / \mathrm{R}-24(\mathrm{n}=5)$, and I/R-48 $(\mathrm{n}=5)$ groups plotted for 11 brain regions. Values are mean $\pm \mathrm{SD}$. $* P<0.05$ vs. nonischemic group, $+P<0.05$ vs. I/R-4 group. 


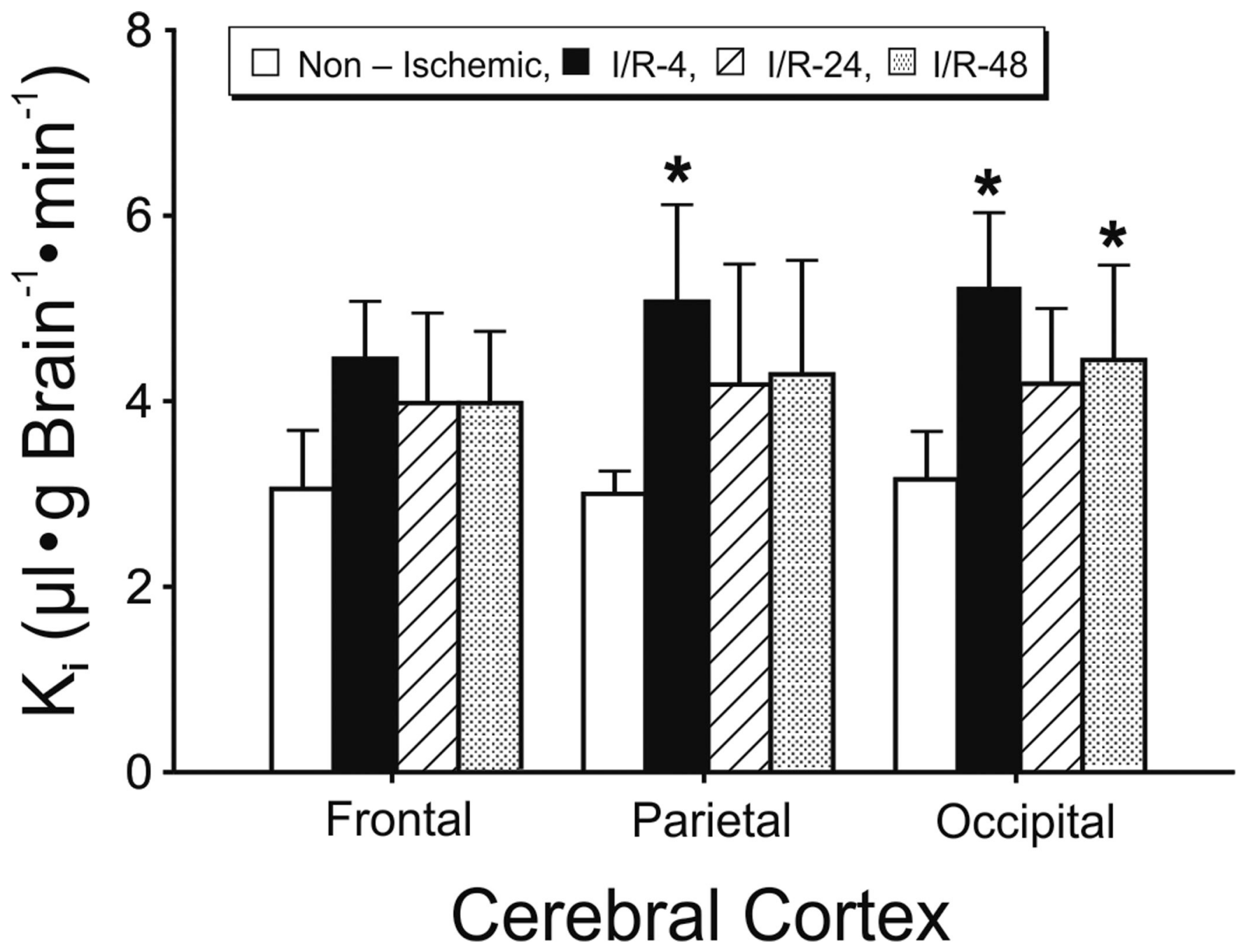

Figure 3.

Blood-to-brain transfer constants $\left(K_{i}\right)$ in the non-ischemic (n=5), I/R-4 (n=5), I/R-24 (n=5), and $\mathrm{I} / \mathrm{R}-48(\mathrm{n}=5)$ groups plotted for the frontal, parietal and occipital cerebral cortices. Values are mean $\pm \mathrm{SD}$. $* P<0.05$ vs. non-ischemic group. 
$\square$ Non - Ischemic (C), $\square / R-4, \square I / R-24, \square / / R-48$
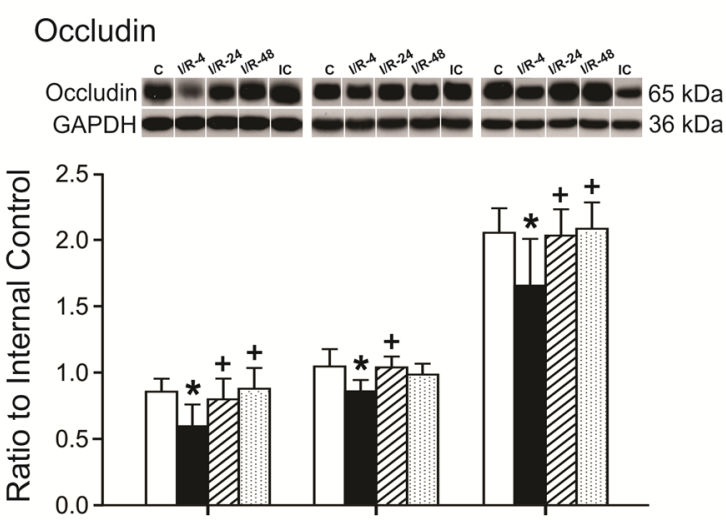

B Claudin-1
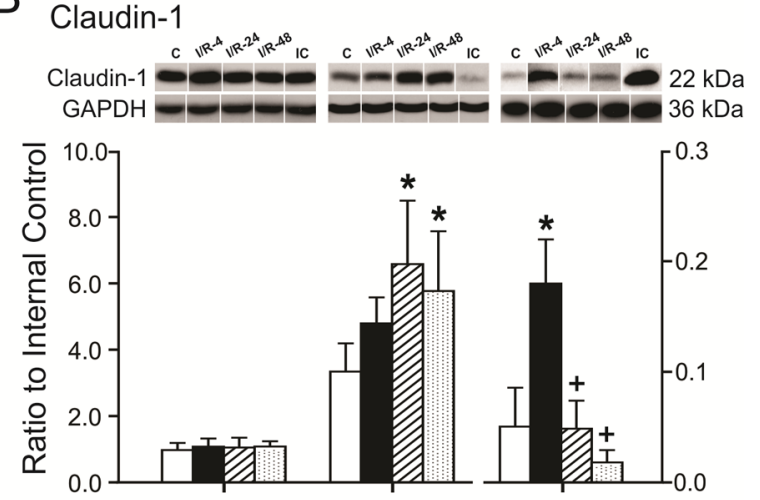

C Claudin-5

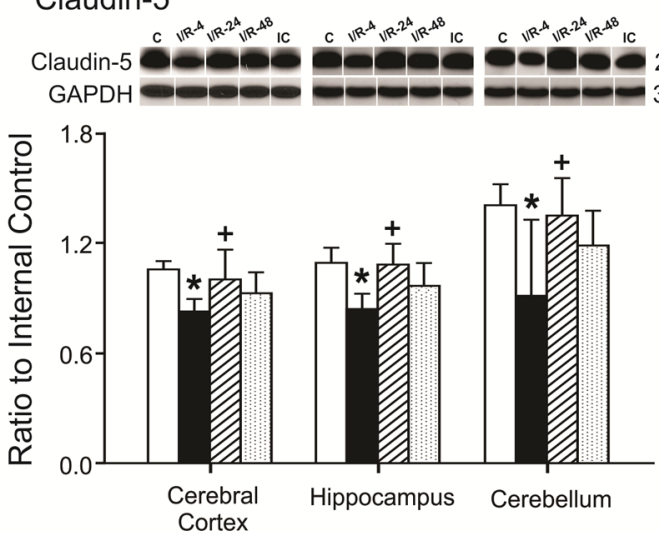

Figure 4.

Tight junction protein expression in the cerebral cortex, hippocampus, and cerebellum. Group legends and numbers as for figure 2. A. Occludin, B. Claudin-1, and C. Claudin-5. Representative Western immunoblot shown for each tight junction protein; IC indicates the internal control standard protein derived from the same adult cerebral cortex. The extracts from the cerebral cortex, hippocampus, and cerebellum from the different treatment groups were placed on different immunoblots. Therefore, for the purpose of illustration, the immunoblot that most closely represented the mean value of the bar graph for each protein and brain region of each group was selected for illustration above the bar graph. GAPDH is 
also shown as a loading control. Values are expressed as mean \pm SD. $* P<0.05$ vs. nonischemic group, $+P<0.05$ vs. I/R-4 group. 


\section{A}

Non - Ischemic (C), घ I/R-4, $\square$ I/R-24, 圆 I/R-48
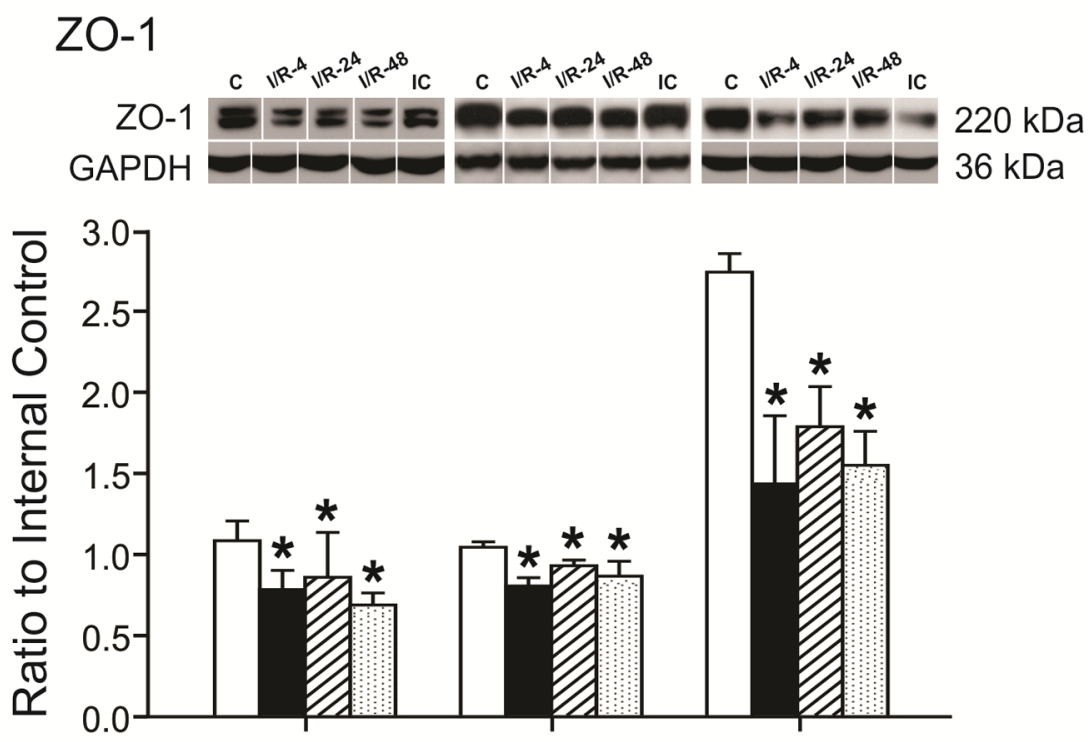

B
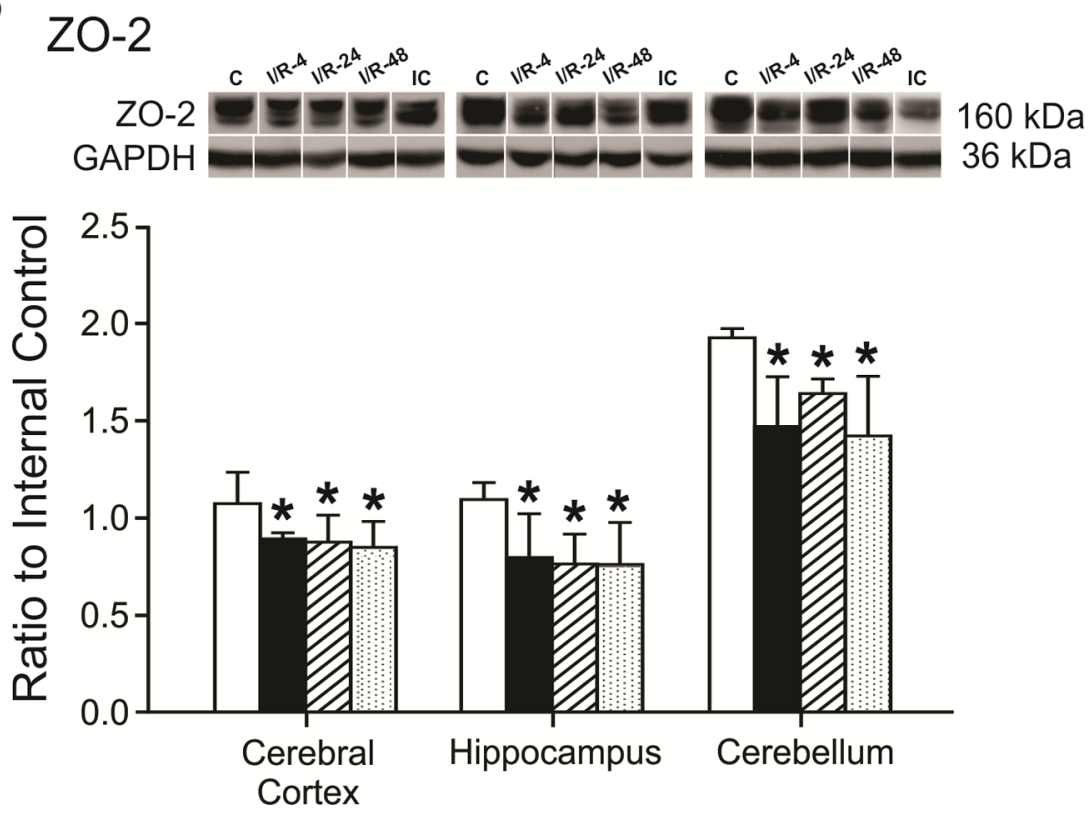

Figure 5.

Tight junction protein expression in the cerebral cortex, hippocampus, and cerebellum. Group legends and numbers as for figure 2. A. ZO-1, B. ZO-2 in the non-ischemic, I/R-4, I/ R-24, and I/R-48 groups. Representative Western immunoblot shown for each tight junction protein; IC indicates the internal control standard protein derived from the same adult cerebral cortex. Values are expressed as mean \pm SD. $* P<0.05$ vs. non-ischemic group. 


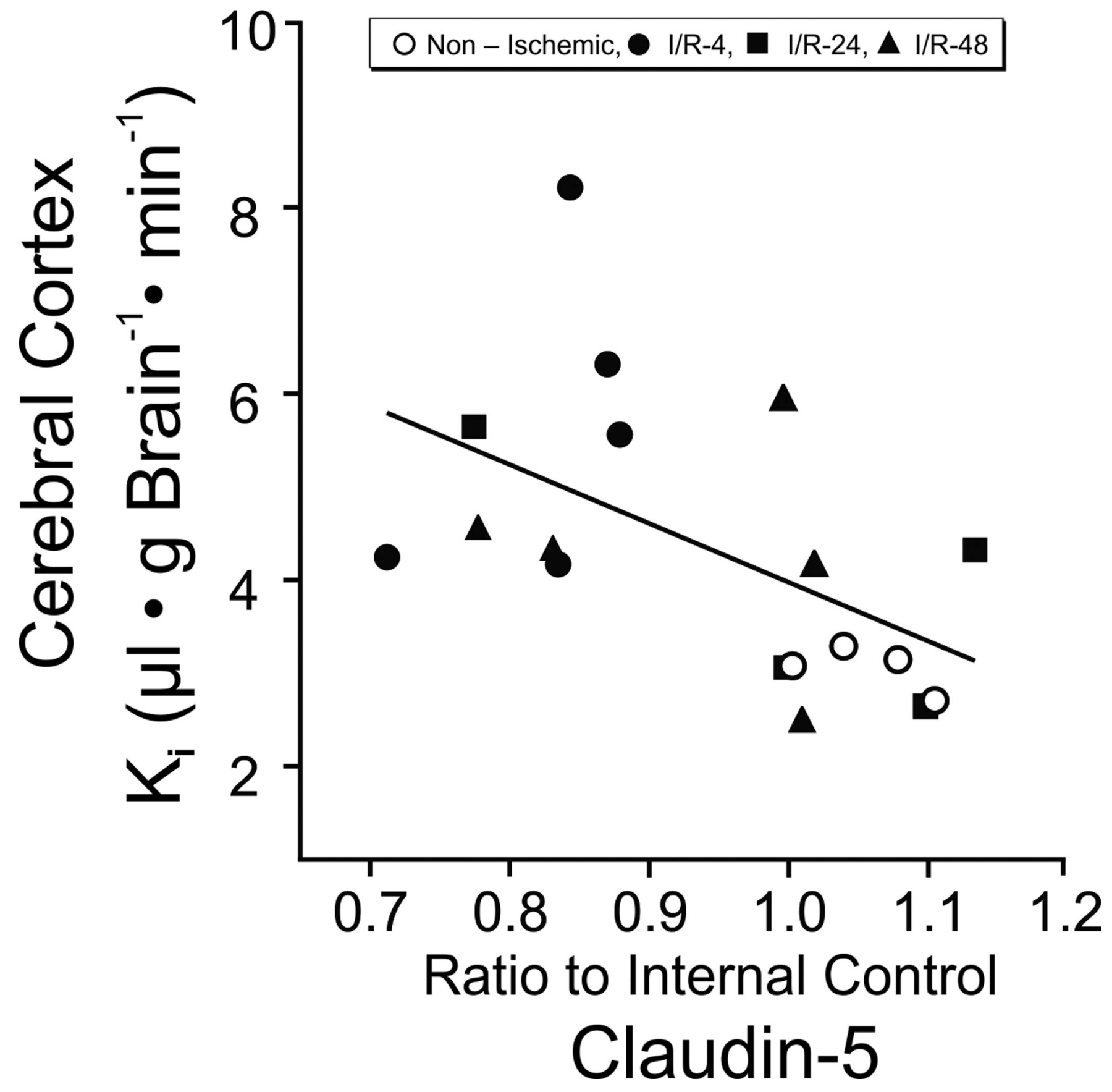

Figure 6.

$K_{i}$ values measured with AIB in the non-ischemic (n=4), I/R-4-treated (n=5), I/R-24-treated $(\mathrm{n}=4)$, and $\mathrm{I} / \mathrm{R}-48$-treated $(\mathrm{n}=5)$ fetuses plotted against claudin-5 protein expression in the cerebral cortex. Stepwise multiple regression analysis using the Dummy coding variables, $r$ $=-0.54, \mathrm{n}=18, P<0.05$. 


\section{Table 1}

The days of gestation, body, and brain weights of the ovine fetuses.

\begin{tabular}{lcccc}
\hline & $\begin{array}{c}\text { Sham Control } \\
(\mathbf{N}=\mathbf{5})\end{array}$ & $\begin{array}{c}\text { I/R-4 } \\
(\mathbf{N}=\mathbf{5})\end{array}$ & $\begin{array}{c}\text { I/R-24 } \\
(\mathbf{N = 5})\end{array}$ & $\begin{array}{c}\text { //R-48 } \\
(\mathbf{N}=\mathbf{5})\end{array}$ \\
\hline Gestation (days) & $127 \pm 2$ & $126 \pm 1$ & $126 \pm 2$ & $127 \pm 1$ \\
Brain weight $(\mathrm{g})$ & $42.7 \pm 9.6$ & $39.8 \pm 2.5$ & $35.7 \pm 10.4$ & $41.6 \pm 5.2$ \\
Body weight $(\mathrm{kg})$ & $3.24 \pm 0.2$ & $2.79 \pm 0.7$ & $2.94 \pm 0.4$ & $3.05 \pm 0.4$ \\
\hline
\end{tabular}

Values are means $\pm \mathrm{SD}, \mathrm{n}=$ number of animals. The gestational ages, brain weights and body weights did not differ among the study groups. 
.

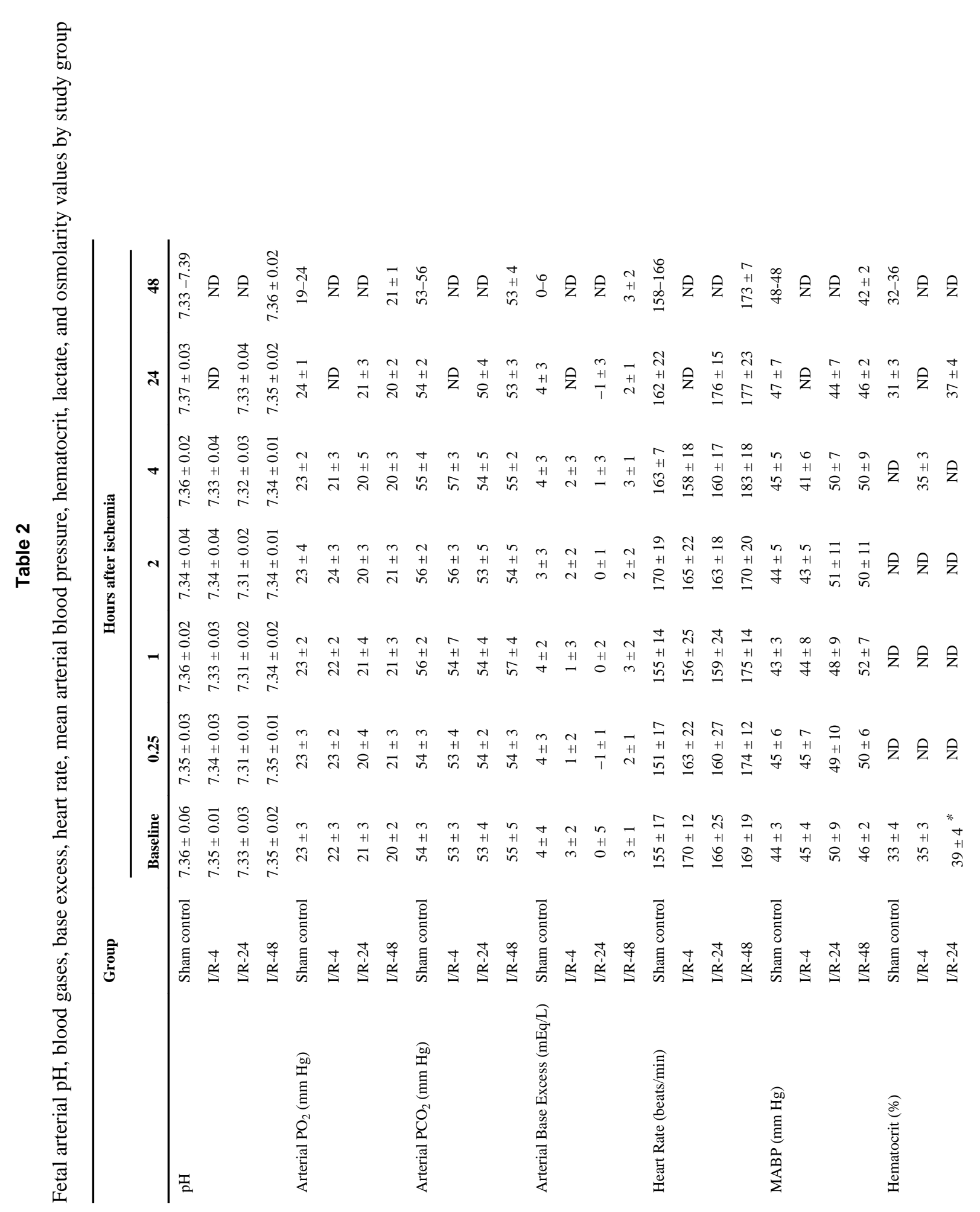




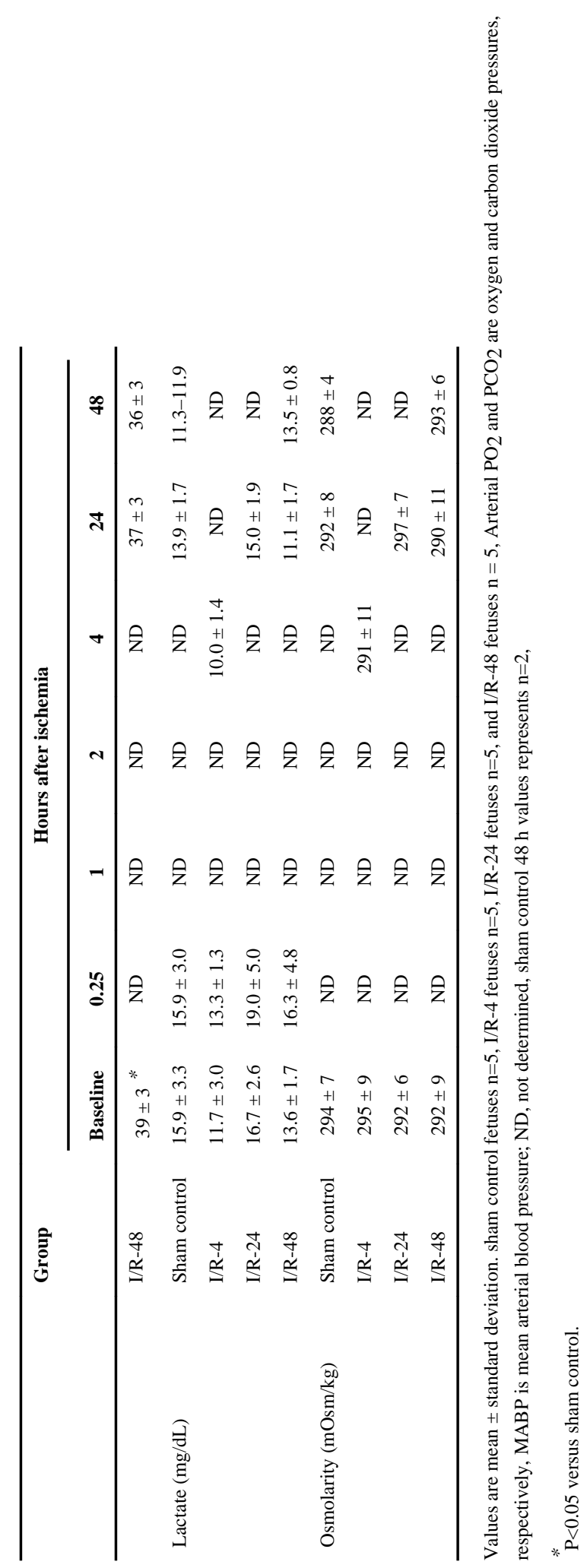


Table 3

Brain blood volume measured with Tc- $99^{\mathrm{M}}$ labeled ovine red blood cells

\begin{tabular}{lcccc}
\hline $\begin{array}{l}\text { Brain Regions } \\
(\boldsymbol{\mu L / g} \text { brain })\end{array}$ & $\begin{array}{c}\text { Sham Control } \\
(\mathbf{N}=\mathbf{5})\end{array}$ & $\begin{array}{c}\text { I/R-4 } \\
(\mathbf{N}=\mathbf{5})\end{array}$ & $\begin{array}{c}\mathbf{I} / \mathbf{R}-\mathbf{2 4} \\
(\mathbf{N}=\mathbf{5})\end{array}$ & $\begin{array}{c}\text { I/R-48 } \\
(\mathbf{N}=\mathbf{5})\end{array}$ \\
\hline Cerebral Cortex & $23.1 \pm 5.8$ & $19.0 \pm 6.1$ & $37.4 \pm 12.3^{*+}$ & $33 \pm 14.5^{+}$ \\
White Matter & $12.4 \pm 4.9$ & $21.5 \pm 15.1$ & $26.5 \pm 3.4 *$ & $15.9 \pm 5.4^{++}$ \\
Caudate Nucleus & $15.6 \pm 1.1$ & $8.6 \pm 5.5$ & $21.6 \pm 7.5$ & $15.5 \pm 14.1$ \\
Hippocampus & $17.1 \pm 3.1$ & $11.8 \pm 5.7$ & $33.4 \pm 20.0$ & $21.0 \pm 11.4$ \\
Cerebellum & $35.6 \pm 13.9$ & $20.8 \pm 3.8$ & $51.1 \pm 11.7+$ & $40.3 \pm 14.6+$ \\
Thalamus & $16.5 \pm 5.8$ & $13.8 \pm 4.9$ & $21.2 \pm 10.9$ & $22.7 \pm 14.4$ \\
Superior Colliculus & $17.1 \pm 3.2$ & $14.8 \pm 6.5$ & $24.4 \pm 7.1$ & $22.9 \pm 14.3$ \\
Inferior Colliculus & $25.9 \pm 12.5$ & $25.0 \pm 11.3$ & $38.3 \pm 22.3$ & $34.3 \pm 18.9$ \\
Pons & $32.9 \pm 20.8$ & $18.3 \pm 7.8$ & $40.8 \pm 29.0$ & $26.1 \pm 15.0$ \\
Medulla & $25.3 \pm 11.7$ & $17.0 \pm 4.1$ & $55.8 \pm 39.3$ & $29.3 \pm 15.9$ \\
Spinal cord & $22.5 \pm 7.9$ & $24.0 \pm 7.2$ & $33.4 \pm 18.3$ & $21.1 \pm 7.8$ \\
\hline
\end{tabular}

Values are means $\pm \mathrm{SD}, \mathrm{n}=$ number of animals.

${ }^{*} P<0.05$ vs. sham operated control group,

${ }^{+} P<0.05$ vs. I/R-4 group,

${ }^{++} P<0.05$ vs. I/R-24 group. 


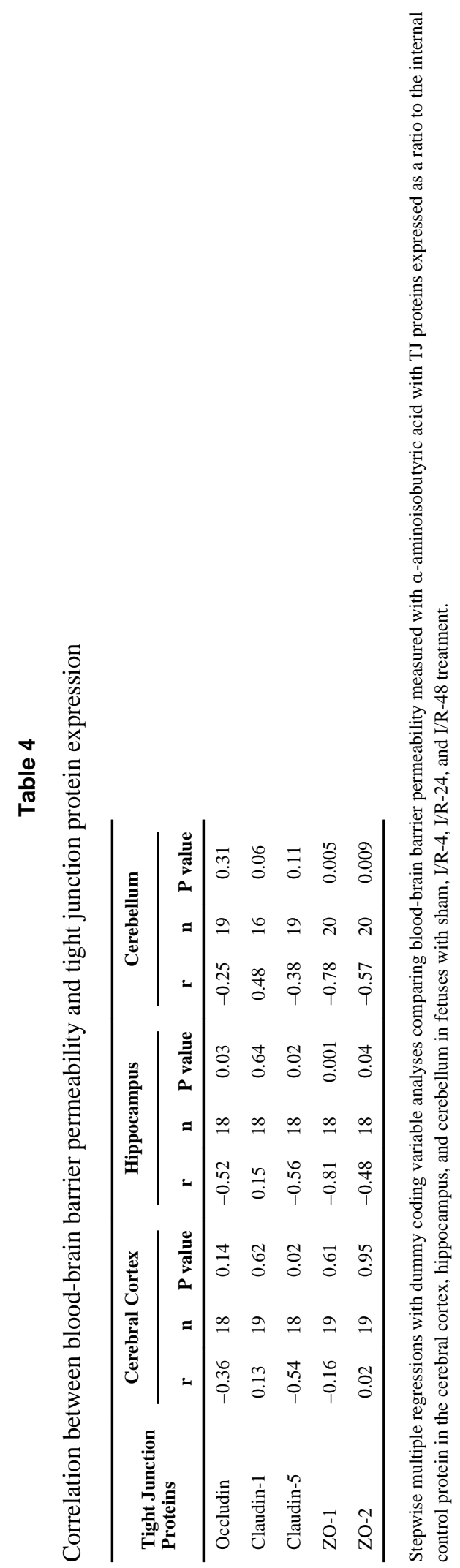

Neuroscience. Author manuscript; available in PMC 2013 December 13. 